\title{
The Critical Role of Intrinsic Membrane Oscillations
}

\author{
Sang-Hun Lee $\quad$ Francisco J. Urbano ${ }^{a, c} \quad$ Edgar Garcia-Rilla \\ aCenter for Translational Neuroscience, and bepartment of Neurology,University of Arkansas for Medical \\ Sciences, Little Rock, AR, USA, and 'IFIBYNE, University of Buenos Aires, Buenos Aires, Argentina
}

\section{Key Words}

Bottom-up gamma - N-type channel - Parafascicular nucleus - Pedunculopontine nucleus • P/Q-type channel $\cdot$ Subcoeruleus nucleus

\begin{abstract}
Intrinsic, rhythmic subthreshold oscillations have been described in neurons of regions throughout the brain and have been found to influence the timing of action potentials induced by synaptic inputs. Some oscillations are sodium channel-dependent while others are calcium channel-dependent. These oscillations allow neurons to fire coherently at preferred frequencies and represent the main mechanism for maintaining high frequency network activity, especially in the cortex. Because cortical circuits are incapable of maintaining high frequency activity in the gamma range for prolonged periods, those processes dependent on continuous gamma band activity are subserved by subthreshold oscillations. As such, intrinsic oscillations, coupled with synaptic circuits, are essential to prolonged maintenance of such functions as sensory perception and "binding", problem solving, memory, waking, and rapid eye movement (REM) sleep.

\section{Introduction}

Intrinsic membrane oscillations were discovered in 1986 [1], and, despite a number of excellent studies describing the critical role intrinsic membrane oscillations play, many neuroscientists are unaware of their importance, especially the role of gamma band for higher cognitive function. This mini-review will address the concept that intrinsic oscillations influence the timing of action potentials (AP) induced by synaptic inputs, and represent the main mechanism for maintaining high frequency network activity, especially in the cortex. This is because cortical circuits appear incapable of maintaining gamma frequencies using 
only synaptic inputs. We include a thorough description of findings on intrinsic properties and their underlying mechanisms in mesopontine and hippocampal regions not described in detail elsewhere. These are critical regions that appear to impart high frequency influence on higher centers, thus modulating the incidence and maintenance of gamma activity at the level of the cortex.

\section{History}

Rhythmic subthreshold oscillations were first described in the inferior olive [1]. They were calcium-dependent and fired at 1-20 Hz. Soon after, subthreshold oscillations were discovered in entorhinal cortex and these fired in the theta range and were sodiumdependent [2]. These were followed by findings demonstrating gamma band subthreshold oscillations in the cortex and thalamus, both calcium-dependent $[3,4]$. Other groups described subthreshold oscillations in the entorhinal cortex [5, 6], and olfactory bulb [7], as well as the dorsal cochlear nucleus [8]. Importantly, these studies established that subthreshold oscillations influenced the timing of APs resulting from synaptic inputs, and triggered the exact occurrence of APs. That is, these membrane oscillations dictated the timing of firing of APs in a circuit [9]. While the amplitude of these oscillations may be low, in the 1-5 mV range, APs are more likely to reach AP threshold, facilitating firing that occurs at the peaks of the oscillations, providing a stable frequency for ensembles of cells [9].

\section{Cortical Synaptic Limits}

Sensory perception, problem solving, memory, waking, and rapid eye movement (REM) sleep have all been proposed to involve gamma frequency oscillations [10-14]. Moreover, such coherent events have been proposed to occur at cortical [15], or thalamocortical levels [3]. That is, some of this activity depends on cortico-cortical associations, as well as reverberating cortico-thalamo-cortical activity [16]. The mechanisms involved include inhibitory cortical interneurons manifesting intrinsic oscillatory activity at gamma frequencies $[3,17]$, and many were found to be electrically coupled [18]. Fast rhythmic bursting pyramidal neurons, some of which are electrically coupled, exhibit intrinsic oscillations [19]. The synchronous activation at gamma band across thalamocortical $[20,21]$, and other neuronal groups appears to contribute to the merger, or "binding", of information from separate cortical regions [22]. Conversely, disturbances in gamma oscillations are thought to be present in diseases like schizophrenia and Alzheimer's disease [16, 23-25]. Gamma activity is known to occur occasionally during slow wave sleep states and anesthesia, but their brief manifestation of gamma activity may not be sufficient to maintain consciousness [26]. That is, consciousness may be associated with continuous or maintained gamma band activity, but not during interrupted gamma activity [27]. In conclusion, cortical circuits must maintain reverberation at gamma frequencies for prolonged periods for perception and consciousness to occur.

However, there is an unstated assumption that cortical synapses can maintain corticocortical association and thalamocortical reverberating signaling at gamma frequencies for prolonged periods. But, cortical synaptic connections alone may not be able to maintain circuit firing at gamma frequencies $(\sim 30-90 \mathrm{~Hz})$, so that intrinsic membrane properties appear essential to the maintenance of gamma band activity. For example, considering the primary visual pathway, which manifests high synaptic security, flicker fusion of visual inputs is evidence that cortical circuits cannot "follow" individual visual stimuli presented at rates above $35 \mathrm{~Hz}$ [28]. Primary auditory cortex evoked responses can follow stimuli presented up to about $20 \mathrm{~Hz}$ [29]. On the other hand, cells with intrinsic membrane properties, coupled with synaptic interactions, may be what allows the circuit as a whole to fire at a high frequency, and is necessary for maintaining high frequencies across the circuit, especially in the gamma range. 
Fig. 1. Two cell groups, in one case the population has coherent subthreshold oscillations (A) and in the other, no oscillations are present (B). In both cell groups, output cells receive common inputs, and are electrically connected to adjacent cells through gap junctions. Thus, coherent subthreshold oscillations can arise if each cells manifest subthreshold oscillations.

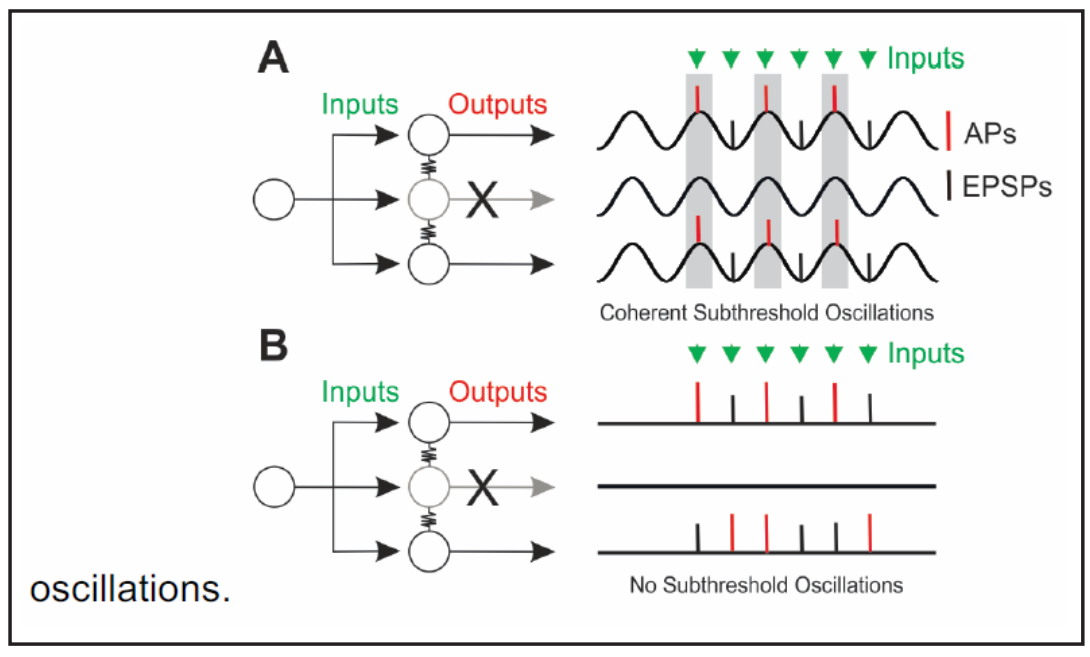
Due to subthreshold oscillations most cells can discharge coherent action potentials at the preferred frequency if excitatory inputs arrive around the peaks when neuronal excitability is high (indicated by the overlapping regions with solid gray bars). In contrast, the cells do not discharge action potentials if excitatory inputs arrive around the trough since neuronal excitability is low. If a synapse fails in one circuit (the middle cell marked by X), the other layers maintain the preferred frequency. If the synapse recovers from the synaptic failures, the circuit ultimately regains coherent firing at that frequency. In contrast, it is likely that neurons, which do not manifest intrinsic subthreshold oscillations, show disrupted coherence of action potential discharges (B), whereas the firing frequency is similar to that of the cell group shown in A. While synaptic failures may not often occur at low frequencies below beta, they will certainly occur at gamma frequencies, particularly in the cortex.

Thus, subthreshold oscillations help circuits maintain a stable frequency rather than generating a range of different frequencies. This point is illustrated in Figure 1, in which two cell groups, in one case the population has subthreshold oscillations (A) and in the other, no intrinsic oscillations are present (B). If there is a synaptic failure from the input to the middle output cell (Xs), the other two output cells will maintain a preferred firing frequency in the case in which oscillations are present. However, in the absence of intrinsic oscillations, the two output cells in Figure 1B will fire at non-coherent times, failing to maintain a stable high frequency.

\section{Ubiquitous Gamma}

The cortex and thalamus are not the only regions that manifest gamma frequency activity. Both the hippocampus and the cerebellum possess the intrinsic and synaptic properties necessary for generating gamma band oscillations. There is an association between hippocampal oscillatory activity in the gamma range $(30-60 \mathrm{~Hz})$ and afferents from the entorhinal cortex [30]. As mentioned above, entorhinal cortex neurons oscillate at gamma frequencies, suggesting that these afferents are critical for maintaining gamma oscillations in the hippocampus [31]. Gamma frequency activity of cells in the CA1 area has two components, fast $(>65 \mathrm{~Hz})$ and slow $(\sim 25-60 \mathrm{~Hz})$ components that characterize the CA1 and CA3 subfields, respectively [32]. It has been proposed that, on the one hand, CA1 gamma oscillations from entorhinal cortex at very high frequency are involved in providing information about object and place recognition in rodents [33]. On the other hand, slow gamma oscillations from CA1 are locked to slower frequencies in the CA3 area in charge of memory storage [32,34]. That is, the two bands subserve different functions. 
Lee/Urbano/Garcia-Rill: Role of Intrinsic Oscillations

The Purkinje cell layer around the apex of the cerebellar lobule manifests gamma band activity $[35,36]$. Critical for gamma oscillation generation in Purkinje cells are GABA but not glutamate receptors [35]. Coherence between the cerebral cortex and cerebellar cortex at gamma frequencies is present during the performance of a manual precision grip task in monkeys [37]. In addition, cerebello-thalamic activity appears synchronized with neocortical activity at gamma frequencies [38]. Moreover, it was suggested that both cerebellar and thalamo-cortical networks oscillate at similar frequencies to enable coherent information exchange between regions [36].

Gamma band activity in the basal ganglia was observed to lead coherent activity in the cerebral cortex $[39,40]$. Several groups concluded that motor cortex gamma synchronization reflects arousal-related activity that enables the initiation of movement [41-43]. Therefore, a region such as the reticular activating system (RAS), which is in charge of arousal, and the thalamus, may together play an early role in the facilitation of movement [44].

\section{Bottom-up Gamma}

We found that the pedunculopontine nucleus (PPN), in charge of waking and REM sleep, two states exhibiting gamma frequency activity in the EEG, possesses neurons manifesting gamma frequency activity when stimulated [45]. There is considerable evidence that PPN cells fire at gamma frequencies. Gamma band activity has been observed in the cortical EEG of the cat in vivo when the animal is active [17]; in the region of the PPN in humans during stepping, but not at rest [46]; and firing at low frequencies $\sim 10 \mathrm{~Hz}$ at rest in the primate, but firing at gamma frequencies when the animal woke up, or when the animal began walking on a treadmill [47]. Thus, the same cells were involved in both arousal and motor control in the PPN in vitro, in vivo, and across species, including man. We discovered that every PPN neuron exhibited gamma band activity via high threshold, voltage-dependent calcium channels [48]. Later, we found that $\sim 50 \%$ of the cells have both P/Q- and N-type calcium channels, while $\sim 25 \%$ have only one of the two channels [49]. Early studies (reviewed in [50]), had shown that PPN neurons fire in relation to states of arousal such as "Wake-REM on" cells firing during both waking and REM sleep, while others fire only during waking called "Wake on" cells, and "REM on" cells fire only during REM sleep. We proposed that "Wake-REM on" neurons have both $\mathrm{N}$ - and P/Q-type calcium channels, that "Wake on" cells have only P/Qtype channels, and that "REM on" neurons have only N-type channels [50].

The original description of the RAS described the effect of electrical stimulation as inducing "tonic" or "continuous" arousal [51]. Later studies showed that lesions of this region would eliminate "tonic" arousal [52]. Such tonic activity in the PPN probably requires both the channels capable of fast oscillations and the circuitry that involves activating these channels for the maintenance of gamma band activity in the RAS [3, 9, 48, 50, 53-55]. We proposed that the sensory input to the RAS during waking provides the continuous activation of the RAS that allows the maintenance of the background of bottom-up gamma activity. Such activity is necessary to support the process that reliably assesses the world around us on a continuous basis, that is, it is essential for the process of preconscious awareness.

Bottom-up or feed forward brain processes have been proposed to depend on sensory events such as stimuli that activate lower brain centers. The information rises to higher centers to promote perception. Top-down or feedback processing refers to the influence imposed by higher centers on the perception of and attention to incoming stimuli. Gamma frequencies for generating bottom-up, and beta frequencies for inducing top-down, processes were proposed as feed forward and feedback channels, respectively, using different frequency bands [56]. The PPN is likely an early step of the generation of bottom-up gamma activity, which it relays to the intralaminar thalamus. We found that every cell in the parafascicular nucleus manifested high threshold calcium channels [57], a region known to relay gamma activity to the cortex. Cells in the Subcoeruleus region exhibited sodium-dependent gamma oscillations [45], a region known to relay gamma activity to the hippocampus. 
Fig. 2. Diagram of bottom-up gamma projections. Sensory input activates pedunculopontimne nucleus (PPN) dendrites. All PPN cells have N-type channeland/or P/Q-type channel-dependent subthreshold gamma oscillations and project to the parafascicular nucleus in the intralaminar thalamus (ILT) adjacent to the fasciculus retroflexus (Fr), which projects to upper layers of the cortex (Cx). The PPN also projects to the Subcoeruleus nucleus dorsalis (SubCD), which manifests sodium (Na) channel-dependent subthreshold gamma oscillations (STO) and

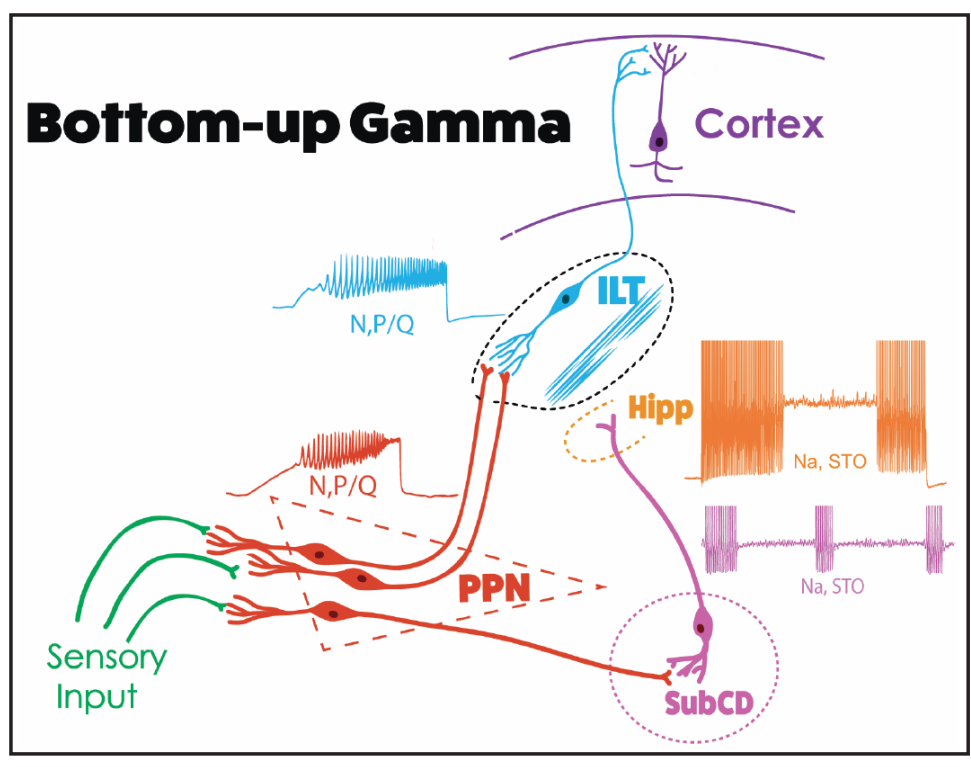
projects to the hippocampus (Hipp). The hippocampus also manifests sodium channel-dependent subthreshold gamma oscillations.

Figure 2 illustrates the organization of arousal-related structures generating bottomup gamma activity during waking and REM sleep. Sensory input activates PPN neurons, all of which manifest N-type and/or P/Q-type mediated intrinsic membrane oscillations. This information is relayed to the intralaminar thalamus, specifically the parafascicular nucleus, which itself manifests similar calcium channel-dependent intrinsic oscillations. The intralaminar thalamus sends its projections to the upper layers of the cortex. Also, the PPN sends descending projections, especially during REM sleep, to the Subcoeruleus nucleus that manifests sodium-dependent subthreshold oscillations and projects to the hippocampus. How can the synchrony in the gamma oscillations of multiple cell assemblies in above mentioned brain areas be achieved, especially considering the long axon conductance delays? There are excellent review articles describing the mechanisms underlying interregional coherence of network oscillations (see [58] and [56]). In general, it is thought that axon collaterals of glutamatergic projection neurons (e.g., [59]), long-range interneurons (e.g., [60]), and a third region, which is reciprocally connect to two regions (e.g., [61]), contribute to the synchrony between spatially discrete oscillators. Thus, interregional temporal coordination between spatially separate brain regions described in Figure 2 might be achieved via similar mechanisms to those described above.

The issue of coherence between distant cortical sites has received increased attention. Recent findings showed that gamma band activity at the level of the cortex during waking was characterized by coherence across regions, but gamma band activity in the cortex during REM sleep had an absence of coherence $[62,63]$. In agreement with the latter, injections of the cholinergic agonist carbachol induced REM sleep with cataplexy (alert wakefulness without muscle tone) that was characterized by decreased gamma band coherence in the cortex [64]. Since the brainstem is the origin of REM sleep drive (for review, see [53]), it is likely that the manifestation of gamma band activity during REM sleep at the level of the cortex begins in the brainstem. We should note that carbachol induced REM sleep which led to decreased coherence, while cataplexy (alert wakefulness without muscle tone) induced increased coherence [64]. Since carbachol will activate both the "waking pathway" and the "REM sleep pathway" discussed above, it is not surprising that these injections induced lack of coherence when REM sleep was elicited and increased coherence when alert wakefulness without muscle tone was elicited. We assume that the manifestation of cortical gamma band activity during waking originates at least in part in the brainstem as well. Therefore, this line 
Lee/Urbano/Garcia-Rill: Role of Intrinsic Oscillations

of evidence suggests that, a) brainstem centers drive gamma band activity that is manifested in the cortical EEG; b) during waking, brainstem-thalamic projections are involved in coherence across regions; and c) during REM sleep, brainstem-thalamic projections drive cortical EEG rhythms without coherence between distant sites.

\section{Frequency Specific Hippocampal Interneurons}

In the hippocampus, subtypes of GABAergic interneurons represent $\sim 11 \%$ of the neuronal population in the subregions [65], and are involved in almost all aspects of hippocampal circuit functions, including coordinated network activity (e.g., theta and gamma oscillations) [66]. We recently found that 5 major subtypes of hippocampal interneurons -parvalbumin-expressing basket cells (PVBCs), cannabinoid type 1 receptor-expressing basket cells $\left(\mathrm{CB}_{1} \mathrm{BCs}\right)$, Schaffer collateral-associated cells (SCAs), neurogliaform cells, and ivy cell, each produced distinct frequency bands of sodium-dependent intrinsic oscillations [67]. Specifically, a majority of PVBCs (83\%) produced intrinsic gamma oscillations near their AP thresholds (see Figure 2). However, the remaining $\mathrm{PVBCs}(17 \%), \mathrm{CB}_{1} \mathrm{BCs}, \mathrm{SCAs}$, neurogliaform cells, and ivy cells manifested intrinsic theta, but not gamma, oscillations near their AP thresholds. In the same studies, we demonstrated that a portion of SCAs $(17 \%)$ and neurogliaform cells $(6 \%)$ produced intrinsic beta oscillations $(15-30 \mathrm{~Hz})$. Our findings suggest not only that major subtypes of GABAergic interneurons manifest cell type-specific intrinsic theta, beta, or gamma oscillations, but also that withinsubtype differences in intrinsic membrane oscillations arise in PVBCs, SCAs, and neurogliaform cells. Such information is critical to formulating precise functional models of the generation of specific frequencies related to specific hippocampal operations. Previously [67], we examined the properties of intrinsic oscillations of only 5 of 21 subtypes of GABAergic interneurons in the CA1 subregion. Given that other major subtypes of GABAergic interneurons, e.g., axo-axonic cells, bistratified cells, and oriens-lacunosum moleculare interneurons, are known to be also involved in theta and gamma oscillations [68], future studies should determine the properties of intrinsic oscillations of other interneurons.

How is cortical network activity generated? At least two distinct types of models of network activity have been proposed: intrinsic resonance property-based models and circuit-based models. Our findings of cell type-specific intrinsic oscillations in hippocampal GABAergic interneurons are in general agreement with intrinsic resonance property-based theta and gamma models. Neuronal intrinsic resonance properties cause hippocampal interneurons to produce intrinsic subthreshold oscillations without synaptic interactions [67, 69-71]. Although the precise role of intrinsic oscillations of hippocampal interneurons in coordinated network activity is largely unknown, there is evidence indicating that intrinsic subthreshold oscillations are key factors in network oscillations [44, 48, 72-74]. Thus, we hypothesize that intrinsic oscillations of gamma cells (i.e., $83 \%$ of PVBCs tested; [67]) may facilitate, or even cause, precise timing of APs during network gamma oscillations. This is particularly true if the oscillations of multiple cells synchronize. Intrinsic oscillations arising from PVBCs and neurogliaform cells can be synchronized in the CA1 network level via electrical synapses, since they are highly coupled with their own or other types of GABAergic interneurons [75-79]. On the other hand, intrinsic theta oscillations of theta cells (i.e., 17\% of PVBCs tested; [67], $\mathrm{CB}_{1} \mathrm{BCs}$, SCAs, neurogliaform cells, and ivy cells are conducive to precise AP discharges during hippocampal theta oscillations.

In circuit-based models, GABAergic interneurons are critically involved in gamma oscillations through reciprocal interactions via chemical synapses with pyramidal cells (i.e., pyramidal-interneuron network gamma, as in 'PING' model), or other GABAergic interneurons (i.e., interneuron network gamma, as in 'ING' model) [58]. Similar to models of gamma oscillations, hippocampal theta oscillations are thought to arise primarily from synaptic interactions of GABAergic interneurons with excitatory cells [80-83]. Since not only synaptic and circuit properties of individual neurons, but also intrinsic resonant properties can contribute to hippocampal network activity, the two types of hippocampal models of network activity are not mutually exclusive. 
Since precise roles of intrinsic oscillations of hippocampal GABAergic interneurons in hippocampal network oscillations are largely unknown, experimental and computational studies should determine the roles. Our data on intrinsic oscillatory properties of neurochemically identified GABAergic interneurons will be of critical importance in computational models of hippocampal gamma and theta oscillations. It is reasonable to expect that intrinsic theta and gamma oscillations of GABAergic interneurons in the hippocampus are key factors in network theta and gamma activity if these data are incorporated into existing computational models of the CA1 region, such as an innovative full-scale computational model based on experimental results on intrinsic, synaptic, and circuit properties of neurochemically identified neurons [80]. The critical role of intrinsic subthreshold oscillations in network gamma oscillations has been shown in the olfactory bulb using computational and experimental approaches [72, 84]. Accordingly, future studies should also experimentally determine if intrinsic theta and gamma oscillations of hippocampal interneurons simultaneously occur with hippocampal network activity, and determine if hippocampal interneurons, which generate intrinsic oscillations, fire at the peaks of intrinsic oscillations.

Finally, given that network theta and gamma activity are often compromised in a variety of neurological and psychiatric disorders [85-91], and abnormal activities of hippocampal interneurons are often associated with these diseases [92-100], future research should also determine if disruption of intrinsic oscillations in one or more of the major interneuron subtypes occurs in neuropathological conditions such as epilepsy. The results from such research will provide new insights into the mechanisms underlying compromised hippocampal rhythmogenesis in various diseases, and could provide a basis for novel interventions to restore compromised hippocampal theta and gamma oscillations.

\section{Acknowledgments}

Supported by NIH award P30 GM110702 from the IDeA program at NIGMS. EGR would also like to express profound gratitude to all of the Federal funding agencies, especially NIH and NSF that have continuously funded his lab for the last 40 years. In addition, this work was supported by grants from FONCYT-Agencia Nacional de Promoción Científica y Tecnológica; Préstamo BID 1728 OC.AR. PICT-2016-1728 and UBACYT 2014-2017 \#20120130101305BA (to Dr. Urbano), and by the College of Medicine, University of Arkansas for Medical Sciences (startup funding to S.-H.L.).

\section{Disclosure Statement}

The authors certify that they have no affiliations with or involvement in any organization or entity with any financial interest, or non-financial interest in the subject matter or materials discussed in this manuscript.

\section{References}

1 Llinas R, Yarom Y: Oscillatory properties of guinea-pig inferior olivary neurons and their pharmacological modulation: an in vitro study. J Physiol 1986;376:163-182.

2 Alonso A, Llinas R: Subthreshold Na+-dependent theta-like rhythmicity in entorhinal cortex layer II stellate cells. Nature 1989;342:175-177.

- 3 Llinas R, Grace AA, Yarom Y: In vitro neurons in mammalian cortical layer 4 exhibit intrinsic oscillatory activity in the 10 to $50 \mathrm{~Hz}$ frequency range. Proc Natl Acad Sci USA 1991;88:897-901 
-4 Pedroarena C, Llinas R: Dendritic calcium conductances generate high frequency oscillation in thalamocortical neurons. Proc Natl Acad Sci USA 1997;94: 724-728.

-5 Schmitz D, Gloveli T, Behr J, Dugladze T, Heinemann U: Subthreshold membrane potential oscillations in neurons of deep layers of the entorhinal cortex. Neurosci 1998;85:999-1004.

-6 Agrawal N, Hamam BN, Magistretti J, Alonso A, Ragsdale DS: Persistent sodium channel activity mediates subthreshold membrane potential oscillations and low-threshold spikes in rat entorhinal cortex layer $\mathrm{V}$ neurons. J Gen Physiol 1999;114: 491-509.

7 Desmaisons D, Vincent JD, Lledo PM: Control of action potential timing by intrinsic subthreshold oscillations in the olfactory bulb output neurons. J Neurosci 1999;19:10727-10737

8 Manis PB, Molitor SC, Wu H: Subthreshold oscillations generated by TTX-sensitive sodium currents in dorsal cochlear nucleus pyramidal cells. Exp Brain Res 1999;153:443-451.

9 Llinas R: The intrinsic electrophysiological properties of mammalian neurons: insights into central nervous system function. Science 1988;242:1654-1664.

10 Eckhorn R, Bauer R, Jordan W, Brosch M, Kruse W, Munk M, Reitboek HJ: Coherent oscillations: a mechanism of feature linking in the visual system? Biol Cybern 1988;60:121-130.

11 Gray CM, Singer W: Stimulus-specific neuronal oscillations in orientation columns of cat visual cortex. Proc Natl Acad Sci USA 1989;86:1698-1702.

12 Philips S, Takeda Y: Greater frontal-parietal synchrony at low gamma-band frequencies for inefficient then efficient visual search in human EEG. Int J Psychophysiol 2009;73:350-354.

13 Palva S, Monto S, Palva JM: Graph properties of synchronized cortical networks during visual working memory maintenance. Neuroimage 2009;49:3257-3268.

- 14 Voss U, Holzmann R, Tuin I, Hobson JA: Lucid dreaming: a state of consciousness with features of both waking and non-lucid dreaming. Sleep 2009;32:1191-1200.

-15 Singer W: Synchronization of cortical activity and its putative role in informtion processing and learning. Annu Rev Physiol 1993;55:349-374.

16 Steriade M, Llinás RR : The functional states of the thalamus and the associated neuronal interplay. Physiol Rev 1988;68:649-742.

17 Steriade M, Datta S, Pare D, Oakson G, Curro Dossi RC: Neuronal activities in brain-stem cholinergic nuclei related to tonic activation processes in thalamocortical systems. J Neurosci 1990;10:2541-59.

18 Gibson JR, Beierlein M, Connors BW: Two networks of electrically coupled inhibitory neurons in neocortex. Nature 1999;402:75-79.

19 Cunningham MO, Whittington MA, Bibbig A, Roopun A, LeBeau FE, Vogt A, Monyer H, Buhi EH, Traub RD: A role for fast rhythmic bursting neurons in cortical gamma oscillations in vitro. Proc Natl Acad Sci USA 2004;101:7152-7157.

20 Llinas RR, Leznik E, Urbano FJ: Temporal binding via cortical coincidence detection of specific and nonspecific thalamocortical inputs: a voltage-dependent dye-imaging study in mouse brain slices. Proc Natl Acad Sci USA 2002;99:449-454.

21 Llinas R, Steriade M: Bursting of thalamic neurons and states of vigilance. J Neurophysiol 2006;95:32973308.

22 Llinás RR, Paré D: Of dreaming and wakefulness. Neurosci 1991;44:521-535.

23 Ribary U, Ioannides AA, Singh KD, Hasson R, Bolton JP, Lado F, Mogilner A, Llinas R: Magnetic field tomography of coherent thalamocortical $40-\mathrm{Hz}$ oscillations in humans. Proc Natl Acad Sci USA 1991;88:11037-11041.

24 Stam CJ, van Cappellen van Walsum AM, Pijnenburg YA, Berendse HW, de Munck JC, Scheltens P, van Dik BW.: Generalized synchronization of MEG recordings in Alzheimer's disease: evidence for involvement of the gamma band. J Clin Neurophysiol 2002;19, 562-574.

25 Uhlhaas PJ, Singer W: High-frequency oscillations and the neurobiology of schizophrenia. Dial Clin Neurosci 2013;15:301-313.

26 Vanderwolf $\mathrm{CH}$ : What is the significance of gamma wave activity in the pyriform cortex? Brain Res 2000;877:125-133.

-27 Vanderwolf CH: Are neocortical gamma waves related to consciousness? Brain Res 2000;855:217-224.

28 Davis SW: Auditory and visual flickerfusion as measure of fatigue. Amer J Psychol 1955;68:654-657. 


\section{SIGíNAis}

\begin{tabular}{l}
\hline Neurosignals 2018;26:66-76 \\
\begin{tabular}{l|l}
\hline DOI: $10.1159 / 000493900$ & C 2018 The Author(s). Published by S. Karger AG, Basel \\
Published onlIne: September 28, 2018 & www.karger.com/nsg
\end{tabular} \\
\hline
\end{tabular}

Lee/Urbano/Garcia-Rill: Role of Intrinsic Oscillations

-29 Erwin R, Buchwald JS: Midlatency auditory evoked responses: Differential recovery cycle characteristics. Electroenceph Clin Neurophysiol 1986;64:417-423.

30 Charpak S, Paré D, Llinás RR: The entorhinal cortex entrains fast CA1 hippocampal oscillations in the anaesthetized guinea-pig: role of the monosynaptic component of the perforant path. Eur J Neurosci 1995;7:1548-1557.

31 Chrobak JJ, Buzsáki G: Gamma oscillations in the entorhinal cortex of the freely behaving rat. J Neurosci 1998;18:388-398.

-32 Colgin LL, Denninger T, Fyhn M, Hafting T, Bonnevie T, Jensen O, Moser MB, Moser EI: Frequency of gamma oscillations routes flow of information in the hippocampus. Nature 2009;462:353-357.

-33 Busey TJ, Muir JL, Aggleton JP: Functionally dissociating aspects of event memory: the effects of combined perirhinal and postrhinal cortex lesions on object and place memory in the rat. J Neurosci 1999;19:495-

502.

34 Colgin LL: Mechanisms and Functions of Theta Rhythms. Annu Rev Neurosci 2013;36:295-312.

35 Lang EJ, Sugihara I, Llinás R: Olivocerebellar modulation of motor cortex ability to generate vibrissal movements in rat. J Physiol (Lond) 2006;571:101-120.

- 36 Middleton SJ, Racca C, Cunningham MO, Traub RD, Monyer H, Knopfel T, Schofield IS, Jnekins A, Whittington MA: High-frequency network oscillations in cerebellar cortex. Neuron 2008;58:763-774.

37 Soteropoulos DS, Baker SN: Cortico-cerebellar coherence during a precision grip task in the monkey. J Neurophysiol 2006;95:1194-1206.

-38 Timofeev I, Steriade M: Fast (mainly 30-100 Hz) oscillations in the cat cerebellothalamic pathway and their synchronization with cortical potentials. J Physiol 1997;504:153-168.

39 Lalo E, Thobois S, Sharott A, Polo G, Mertens P, Pogosyan A, Brown P: Patterns of bidirectional communication between cortex and basal ganglia during movement in patients with Parkinson disease. J Neurosci 2008;28:3008-3016.

40 Trottenberg T, Fogelson N, Kuhn AA, Kivi A, Kupsch A, et al: Subthalamic gamma activity in patients with Parkinson's disease. Exp Neurol 2006;200:56-65.

41 Brucke C, Huebl J, Kempf F, Krauss JK, Yarrow et al: Pallidal gamma activity is correlated to movement amplitude in patients with dystonia. Clin Neurophysiol 2008;119:(S1)49.

42 Cheyne G, Ferrari P: MEG studies of motor cortex gamma oscillations: evidence for a gamma "fingerprint" in the brain? Frontiers Human Neurosci 2013;7, \#575.

43 Jenkinson N, Kuhn AA, Brown P: Gamma oscillations in the human basal ganglia. Exp Neurol 2013;245:7276.

44 Garcia-Rill E, D’Onofrio S, Luster B, Mahaffey S, Urbano FJ, Phillips C: The $10 \mathrm{~Hz}$ Frequency: a fulcrum for transitional brain states. Translat Brain Rhyth 2016;1:7-13.

45 Simon C, Kezunovic N, Ye M, Hyde J, Hayar A, Williams D, Garcia-Rill E: Gamma band unit and population responses in the pedunculopontine nucleus. J Neurophysiol 2010;104:463-474.

-46 Fraix V, Bastin J, David O, Goetz L, Ferraye M, Benabid AL, Chabardes S, Pollak P, Debu B: Pedunculopontine nucleus area oscillations during stance, stepping and freezing in Parkinson's disease. PLoS ONE 2013;8:e83919.

47 Goetz L, Piallat B, Bhattacharjee M, Mathieu H, David O, Chabardes S: The primate pedunculopontine nucleus region: towards a dual role in locomotion and waking state. J Neural Transm 2016;123:667-678.

-48 Kezunovic N, Urbano FJ, Simon C, Hyde J, Smith K, Garcia-Rill E: Mechanism behind gamma band activity in the pedunculopontine nucleus (PPN). Eur J Neurosci 2011;34:404-415.

49 Luster B, D’Onofrio S, Urbano FJ, Garcia-Rill E: High-Threshold Ca2+ channels behind gamma band activity in the pedunculopontine nucleus (PPN). Physiol Rep 2015;3:e12431.

-50 Garcia-Rill E, Luster B, D’Onofrio S, Mahaffey S, Bisagno V, Urbano FJ: Implications of gamma band activity in the pedunculopontine nucleus. J Neural Transm 2015;123:655-665.

-51 Moruzzi G, Magoun HW: Brain stem reticular formation and activation of the EEG. Electroenceph Clin Neurophysiol 1949;1:455-473.

-52 Watson RT, Heilman KM, Miller BD, King FA: Neglect after mesencephalic reticular formation lesions. Neurology 1974;24:294-298.

53 Garcia-Rill E: Waking and the Reticular Activating System. New York. Academic Press. ISBN 9780128013854, 2015. 
Lee/Urbano/Garcia-Rill: Role of Intrinsic Oscillations

54 Garcia-Rill E, Kezunovic N, Hyde J, Beck P, Urbano FJ: Coherence and frequency in the reticular activating system (RAS). Sleep Med Rev 2013;17:227-238.

55 Garcia-Rill E, Kezunovic N, D’Onofrio S, Luster B, Hyde J, Bisagno V, Urbano FJ: Gamma band activity in the RAS-intracellular mechanisms. Exp Brain Res 2014;232:1509-1522.

-56 Bastos AM, Vezoli J, Bosman CA, Schoffelen JM, Oostenveld R, Dowdall JR, De Weerd P, Kennedy H, Fries P.: Visual areas exert feedforward and feedback through distinct frequency channels. Neuron 2015;85:390-40.

57 Kezunovic N, Hyde J, Simon C, Urbano FJ, Garcia-Rill E: Gamma band activity in the developing parafascicular nucleus (Pf). J Neurophysiol 2012;107:772-784.

58 Buzsáki G, Wang X-J: Mechanisms of gamma oscillations. Annu Rev Neurosci 2012;35:203-25.

-59 Traub RD, Whittington MA, Stanford IM, Jefferys JGR: A mechanism for generation of long-range synchronous fast oscillations in the cortex. Nature 1996;383:621-624.

60 Buzsáki G, Geisler C, Henze DA, Wang XJ: Interneuron Diversity series: Circuit complexity and axon wiring economy of cortical interneurons. Trends Neurosci 2004;27, 186-193.

61 Vicente R, Gollo LL, Mirasso CR, Fischer I, Pipa G: Dynamical relaying can yield zero time lag neuronal synchrony despite long conduction delays. Proc Natl Acad Sci USA 2008;105:17157-17162.

62 Castro S, Falconi A, Chase M, Torterolo P: Coherent neocortical 40-Hz oscillations are not present during REM sleep. Eur J Neurosci 2013;37:1330-1339.

63 Cavelli M, Castro S, Schwartzkopf N, Chase M, Falconi A, Torterolo P: Coherent cortical oscillations decrease during REM sleep in the rat. Behav Brain Res 2015;281:318-325.

64 Torterolo P, Castro-Zaballa S, Cavelli M, Chase M, Falconi A: Neocortical $40 \mathrm{~Hz}$ oscillations during carbacholinduced rapid eye movement sleep and cataplexy. Eur J Neurosci 2015;281:318-325.

65 Bezaire MJ, Soltesz I: Quantitative assessment of CA1 local circuits: knowledge base for interneuronpyramidal cell connectivity. Hippocampus 2013;23:751-85.

66 Pelkey KA, Chittajallu R, Craig MT, Tricoire L, Wester JC, McBain CJ: Hippocampal GABAergic Inhibitory Interneurons. Physiol Rev 2017;97, 1619-1747.

67 Kang Y-J, Lewis HES, Young MW, Govindaiah G, Greenfield LJ, Garcia-Rill E, Lee SH: Cell type-specific intrinsic perithreshold oscillations in hippocampal GABAergic interneurons. Neuroscience 2018;376:8093.

68 Klausberger T, Somogyi P: Neuronal diversity and temporal dynamics: the unity of hippocampal circuit operations. Science 2008;321:53-7.

69 Cea-del Rio CA, Lawrence JJ, Erdelyi F, Szabo G, McBain CJ: Cholinergic modulation amplifies the intrinsic oscillatory properties of CA1 hippocampal cholecystokinin-positive interneurons. J Physiol 2011;589:60927.

70 Chapman CA, Lacaille JC: Intrinsic theta-frequency membrane potential oscillations in hippocampal CA1 interneurons of stratum lacunosum-moleculare. J Neurophysiol 1999;81:1296-1307.

71 Pike FG, Goddard RS, Suckling JM, Ganter P, Kasthuri N, Paulsen O: Distinct frequency preferences of different types of rat hippocampal neurones in response to oscillatory input currents. J Physiol 2000;529 Pt 1:205-13.

72 Brea JN, Kay LM, Kopell NJ: Biophysical model for gamma rhythms in the olfactory bulb via subthreshold oscillations. Proc Natl Acad Sci USA 2009;106:21954-21959.

-73 Chapman CA, Lacaille JC: Cholinergic induction of theta-frequency oscillations in hippocampal inhibitory interneurons and pacing of pyramidal cell firing. J Neurosci 1999;19:8637-45.

74 Llinas RR: Intrinsic electrical properties of mammalian neurons and CNS function: a historical perspective. Front Cell Neurosci 2014;8:1-14.

75 Armstrong C, Szabadics J, Tamás G, Soltesz I: Neurogliaform cells in the molecular layer of the dentate gyrus as feed-forward $\gamma$-aminobutyric acidergic modulators of entorhinal-hippocampal interplay. J Comp Neurol 2011;519:1476-91.

76 Galarreta M, Hestrin S: A network of fast-spiking cells in the neocortex connected by electrical synapses. Nature 1999;402:72-5.

77 Price CJ, Cauli B, Kovacs ER, Kulik A, Lambolez B, Shigemoto R, Capogna M: Neurogliaform Neurons Form a Novel Inhibitory Network in the Hippocampal CA1 Area. J Neurosci 2005;25:6775-6786.

-78 Simon A, Oláh S, Molnár G, Szabadics J, Tamás G: Gap-Junctional Coupling between Neurogliaform Cells and Various Interneuron Types in the Neocortex. J Neurosci 2005;25:6278-6285. 
79 Tamás G, Buhl EH, Lörincz A, Somogyi P: Proximally targeted GABAergic synapses and gap junctions synchronize cortical interneurons. Nat Neurosci 2000;3:366-371.

80 Bezaire MJ, Raikov I, Burk K, Vyas D, Soltesz I: Interneuronal mechanisms of hippocampal theta oscillations in a full-scale model of the rodent CA1 circuit. Elife 2016;5.

81 Buzsáki G: Theta Oscillations in the Hippocampus. Neuron 2002;33:325-340.

82 Colgin LL: Mechanisms and Functions of Theta Rhythms. Annu Rev Neurosci 2013; 36, 295-312.

83 Ferguson KA, Chatzikalymniou AP, Skinner FK: Combining Theory, Model, and Experiment to Explain How Intrinsic Theta Rhythms Are Generated in an In Vitro Whole Hippocampus Preparation without Oscillatory Inputs. eNeuro 2017;4:e0131.

-84 Lagier S, Carleton A, Lledo P-M: Interplay between Local GABAergic Interneurons and Relay Neurons Generates Oscillations in the Rat Olfactory Bulb. J Neurosci 2004;24:4382-4392.

85 Bettus G, Wendling F, Guye M, Valton L, Jean R, Chauvel P, Bartolomei F: Enhanced EEG functional connectivity in mesial temporal lobe epilepsy. Epilepsy Res 2008;81:58-68.

86 Dugladze T, Vida I, Tort AB, Gross A, Otahal J, Heinemann U, Kopell NJ, Gloveli T: Impaired hippocampal rhythmogenesis in a mouse model of mesial temporal lobe epilepsy. Proc Natl Acad Sci USA. 2007;104:17530-17535.

87 Gonzalez-Burgos G, Cho RY, Lewis DA: Alterations in cortical network oscillations and parvalbumin neurons in schizophrenia. Biol Psychiatry 2015;77:1031-1040.

88 Groticke I, Hoffmann K, Loscher W: Behavioral alterations in a mouse model of temporal lobe epilepsy induced by intrahippocampal injection of kainate. Exp Neurol 2008;213, 71-83.

89 Mathalon DH, Sohal VS: Neural Oscillations and Synchrony in Brain Dysfunction and Neuropsychiatric Disorders. JAMA Psychiatry 2015;72:840.

90 Lega B, Dionisio S, Bingaman W, Najm I, Gonzalez-Martinez J: The gamma band effect for episodic memory encoding is absent in epileptogenic hippocampi. Clin Neurophysiol 2014;126:1-7.

-91 Shuman T, Amendolara B, Golshani P: Theta Rhythmopathy as a Cause of Cognitive Disability in TLE. Epilepsy Curr 2017;17:107-111.

-92 Barnes SA, Pinto-Duarte A, Kappe A, Zembrzycki A, Metzler A, Mukamel EA, Lucero J, Wang X, Sejnowski TJ, Markou A, Behrens MM: Disruption of mGluR5 in parvalbumin-positive interneurons induces core features of neurodevelopmental disorders. Mol Psychiatry 2015;20:1161-1172.

\$3 Chen K, Ratzliff A, Hilgenberg L, Gulys A, Freund TF, Smith M, Dihn TP, Plomelli D, Mackie K, Soltsz I: Long-term plasticity of endocannabinoid signaling induced by developmental febrile seizures. Neuron 2003;39:599-611.

$\$ 94$ Cho KKA, Hoch R, Lee AT, Patel T, Rubenstein JLR, Sohal VS: Gamma rhythms link prefrontal interneuron dysfunction with cognitive inflexibility in dlx5/6+/- mice. Neuron 2015;85:1332-1343.

-95 Földy C, Malenka RC, Südhof TC: Autism-associated neuroligin-3 mutations commonly disrupt tonic endocannabinoid signaling. Neuron 2013;78:498-509.

-96 Glausier JR, Fish KN, Lewis DA: Altered parvalbumin basket cell inputs in the dorsolateral prefrontal cortex of schizophrenia subjects. Mol Psychiatry 2014;19:30-36.

-97 Lopez-Pigozzi D, Laurent F, Brotons-Mas JR, Valderrama M, Valero M, Fernandez-Lamo I, Cid E, GomezDominguez D, Gal B, Menendez de la Prida L: Altered oscillatory dynamics of CA1 parvalbumin-basket cells during theta-gamma rhythmopathies of temporal lobe epilepsy. eNeuro 2016;3.

$\$ 98$ Mahar I, Albuquerque MS, Mondragon-Rodriguez S, Cavanagh C, Davoli MA, Chabot J-G, Williams S, Mechawar N, Quirion R, Krantic S: Phenotypic Alterations in Hippocampal NPY- and PV-Expressing Interneurons in a Presymptomatic Transgenic Mouse Model of Alzheimer's Disease. Front Aging Neurosci 2017;8:327.

99 Orbán-Kis K, Szabadi T, Szilágyi T: The loss of Ivy cells and the hippocampal input modulatory O-LM cells contribute to the emergence of hyperexcitability in the hippocampus. Rom J Morphol Embryol 2015;56:155-61.

100 Wyeth MS, Zhang N, Mody I, Houser CR: Selective reduction of cholecystokinin-positive basket cell innervation in a model of temporal lobe epilepsy. J Neurosci 2010;30:8993-9006. 